\title{
A cell suspension based uptake method to study high affinity glucosinolate transporters
}

\author{
Deepti M. Nambiarr ${ }^{1}$, Juhi Kumari ${ }^{1}$, Gulab C. Arya ${ }^{1}$, Amarjeet K. Singh ${ }^{2}$ and Naveen C. Bisht ${ }^{* *}$
}

\begin{abstract}
Background: Glucosinolates are an important class of secondary metabolites characteristic to the order Brassicales. They are known to play a major role in plant defense and from the human perspective, can be anticarcinogenic or antinutritive. GTRs are plasma-membrane localized high affinity glucosinolate transporters, which are important components of the source (leaf) to sink (seed) translocation of intact glucosinolates in members of Brassicaceae family. GTRs are identified as major candidates for Brassica crop improvement, thus dictating a need for their functional characterization. However, currently there are limitations in availability of heterologous assay systems for functional characterization of plant secondary metabolite transporters. To date, the animal-based Xenopus oocyte system is the best established heterologous system for functional characterization of these transporters. Inherent biochemical and physiological attributes unique to the plant membranes necessitate the need for developing plant-based transporters assay systems as well.
\end{abstract}

Methods: In this study, Agrobacterium mediated transformation was used to develop GTR expressing cotton cell lines (CCL-1) for functional characterization of the Arabidopsis high affinity glucosinolate transporters, AtGTR1 and AtGTR2. Following sub-cellular localization of AtGTRs, we standardized the glucosinolate uptake assays using cell suspension cultures of AtGTR expressing CCL-1 its requirement of $\mathrm{pH}$, salt, and time based glucosinolate uptake. Using the GTR expressing CCL-1, we subsequently performed kinetic analysis of AtGTR1 and AtGTR2 for different glucosinolate substrates, sinigrin, gluconapin and sinalbin.

Results: Several clones expressing each of AtGTR1 and AtGTR2 were obtained showing high level of GTR expression and were maintained through regular sub-culturing. Both AtGTR1 and AtGTR2 are predominantly plasma-localized proteins when overexpressed in CCL-1 cells. Uptake assays were standardized, suggesting that glucosinolate uptake of GTR expressing CCL-1 is robust within the physiological pH range 5-6, and at lower concentration of nitrate salts. GTR expressing CCL-1 cells show increasing glucosinolate accumulation in time course experiment. Kinetic studies over a wide glucosinolate concentrations $(10-800 \mu \mathrm{M})$ revealed that our novel assay system displayed robust GTR-mediated uptake of different glucosinolates and unambiguously helps elucidate the saturable kinetics of GTRs. Our system confirms the high affinity of AtGTRs for both aliphatic and aromatic glucosinolates.

Conclusion: The transporter assay system described in this study holds potential for studying sub-functionalization amongst GTR homologs present across Brassicaceae family. The fast growing CCL-1 cells, confer the benefits of an in vitro system for quick assays and is plant based thus enabling optimal expression without sequence modifications. The efficient functioning of the GTR transporters in the heterologous CCL-1 opens the possibility of using this plant cell suspension system for functional characterization of other metabolite transporters.

*Correspondence: ncbisht@nipgr.ac.in

${ }^{1}$ National Institute of Plant Genome Research, Aruna Asaf Ali Marg, New Delhi 110067, India

Full list of author information is available at the end of the article

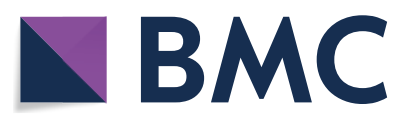

(c) The Author(s) 2020. This article is licensed under a Creative Commons Attribution 4.0 International License, which permits use, sharing, adaptation, distribution and reproduction in any medium or format, as long as you give appropriate credit to the original author(s) and the source, provide a link to the Creative Commons licence, and indicate if changes were made. The images or other third party material in this article are included in the article's Creative Commons licence, unless indicated otherwise in a credit line to the material. If material is not included in the article's Creative Commons licence and your intended use is not permitted by statutory regulation or exceeds the permitted use, you will need to obtain permission directly from the copyright holder. To view a copy of this licence, visit http://creativeco mmons.org/licenses/by/4.0/. The Creative Commons Public Domain Dedication waiver (http://creativecommons.org/publicdomain/ zero/1.0/) applies to the data made available in this article, unless otherwise stated in a credit line to the data. 
Keywords: Cotton cell suspensions, Secondary metabolite transporters, Glucosinolates, GTR transporters, Kinetic analysis

\section{Background}

A prerequisite for functional characterization of plant membrane transporters is a reliable and well standardized biological assay system. To date, yeast is an important heterologous system for plant transporter studies. Availability of mutant strains which lack functional homologues for certain plant primary metabolite transporters makes this system ideal for study of these transporters. The first plant transporter studied using this system was Chlorella HUP1 glucose transporter [20]. However, there are due marked differences between yeast and plant cells. Major problems which can be encountered while using this system for functional characterization of plant plasma membrane proteins are poor expression, retention in intracellular compartments leading to incorrect localization and altered translation which can cause aberrant functioning $[4,6]$. There have been limited attempts towards using this system for study of plant secondary metabolite transporters such as the GTRs. A major hurdle was that detection of substrate uptake by the transporter under investigation required the utilization of the substrate or its metabolite for growth. In this context, attempts at genetic engineering of yeast with sulphatase gene from Helix pomatia or myrosinase gene from Brassica napus, in order to enable cells to use glucosinolate hydrolytic products as a Sulphur source for growth, have as yet been unsuccessful [24]. However, there have been recent reports of limited success towards functional characterization of Abscisic acid transporters using the yeast system. Detection of substrate uptake was enabled through coupling with mass spectrometry based techniques, thus providing scope for future utilization of the yeast system for study of plant secondary metabolite transporters [8].

The Xenopus oocyte is another robust system, currently also the best system for investigating plant secondary metabolite transporters. Glucosinolate transporters (GTRs) were first characterized using this system [14]. Oocytes being endowed with efficient protein translation machinery show optimum expression of the desired protein [13]. This system is amenable to electrophysiological experiments involving transporters since mature oocyte diameter ranges between the ideal values of $1.0-1.33 \mathrm{~mm}$ [3]. This system can be used to develop plant transporter cDNA expression libraries which help in identifying novel transporters [16]. However, fundamental differences such as a more negative resting membrane potential in plant cells and presence of endogenous voltage gated channels such as chloride channels in oocytes, render this system tricky in context of studying the plant membrane transporters.

A heterologous system which is poorly utilized, nonetheless holds promise for use for plant transporter study is the insect cell system. Recombinant Baculovirus infected Sf9 and Sf21 cell lines derived from Spodoptera frugiperda were used to investigate plant $\mathrm{K}+$ channels [5]. Insect cells show high expression of the foreign protein with the requisite post-translational modifications and are compatible with electrophysiological experiments. However, construction and purification of recombinant Baculovirus expression vectors are technically difficult. Moreover, poor documentation of endogenous channels and inability of insect cell membranes to withstand the highly negative membrane potential required for plant transporter study makes the system a less attractive option currently. In the last two decades, BY-2 plant cell system derived from tobacco has been used to investigate the role of plant transporters in biological processes such as auxin efflux and abscisic acid transporters $[2,9,10]$, and holds scope for use in plant transporter characterization. Thus, no single system can suffice for functional characterization of plant transporters. Plant cell microenvironment is inherently different from animal cells and these differences can often translate into differences in expression, localization, regulation and function, particularly that of the membrane transporters. It is therefore desirable to have a plant based assay system for study of plant transporters such as the GTRs.

GTR1 and GTR2 are plasma membrane localized high affinity glucosinolate transporters first characterized in the model plant Arabidopsis thaliana [14]. Electrophysiological experiments characterized GTR transporters as $\mathrm{H}+/$ glucosinolate influx symporters. Based on sequence homology and mechanism of action, these transporters are categorized as members of the proton dependent oligopeptide (POT) family. Having been derived through neo-functionalization in nitrate transporters in course of evolution, they belong to the highly diversified NRT/PTR family. GTR have retained their affinity for nitrates and have high specificity for aromatic and aliphatic glucosinolates [7]. These transporters possibly transport phytohormones such as jasmonoyl-isoleucine and gibberellins [18]. GTR transporters play an important role in phloem loading, leaf distribution as well as rhizosecretion of glucosinolates [12, 14, 25]. These transporters have also 
been recognized as key players in glucosinolate accumulation in sulphur-rich S-cells in phloem cap cells [26]. They are thus important components of the glucosinolate source to sink translocation pathway. GTR transporters have been identified as potential targets in commercially important Brassica crops, for altering the glucosinolate profile towards improvement of the nutritive value of edible parts, without compromising on plant defence [15]. However, the presence of a vast repertoire of functional GTR homologs in polyploid Brassica crops, dictates the need for their functional characterization and structure-function analysis.

In this study, we describe a novel method for functional characterization of two well-known glucosinolate transporters, AtGTR1 and AtGTR2 by heterologously expressing them in a fast-growing cell-suspension line (CCL-1) derived from cotton, Gossypium hirsutum. The CCL-1 lacks endogenous glucosinolate biosynthetic machinery and thus GTR transporters. The GTR transformed cell lines show robust GTR mediated uptake of glucosinolates and are ideal for detailed kinetic studies. The plant cell suspension based uptake method described in this study holds promise for use in structure-function analysis of the diverse GTR transporters and possibly other metabolite transporters.

\section{Results}

Development of GTR expressing cotton cell lines

In order to functionally characterize the glucosinolate transporters (GTRs), we exploited the cotton cell-suspension line $(C C L-1)$, which is a homogenous cell line derived from non-embryogenic calli of cotyledon origin [21]. A flow chart of the procedures adopted in the current study is depicted in Fig. 1. Briefly, Agrobacterium mediated transformation of the fast growing CCL-1 cells was performed with T-DNA constructs comprising of gene specific coding sequences (CDS) of Arabidopsis AtGTR1 and AtGTR2 under the CaMV35S constitutive promoter and Basta resistance gene $(B l p R)$ as the selection marker (Fig. 2a). CCL-1 cells with T-DNA construct lacking any GTR insert served as vector control. Numerous putative transformants were obtained for each construct after two-three rounds of sub-culture on the selection media, at 14 days interval each (Fig. 2b). T-DNA insertion into genomes of putative CCL-1 transformants for vector control, AtGTR1 and AtGTR2 was first confirmed through amplification of $B l p R$ gene from the genomic DNA of the mentioned, using gene specific internal primers (Table 2). Further, incorporation of the AtGTR1 and AtGTR2 genes was also checked through

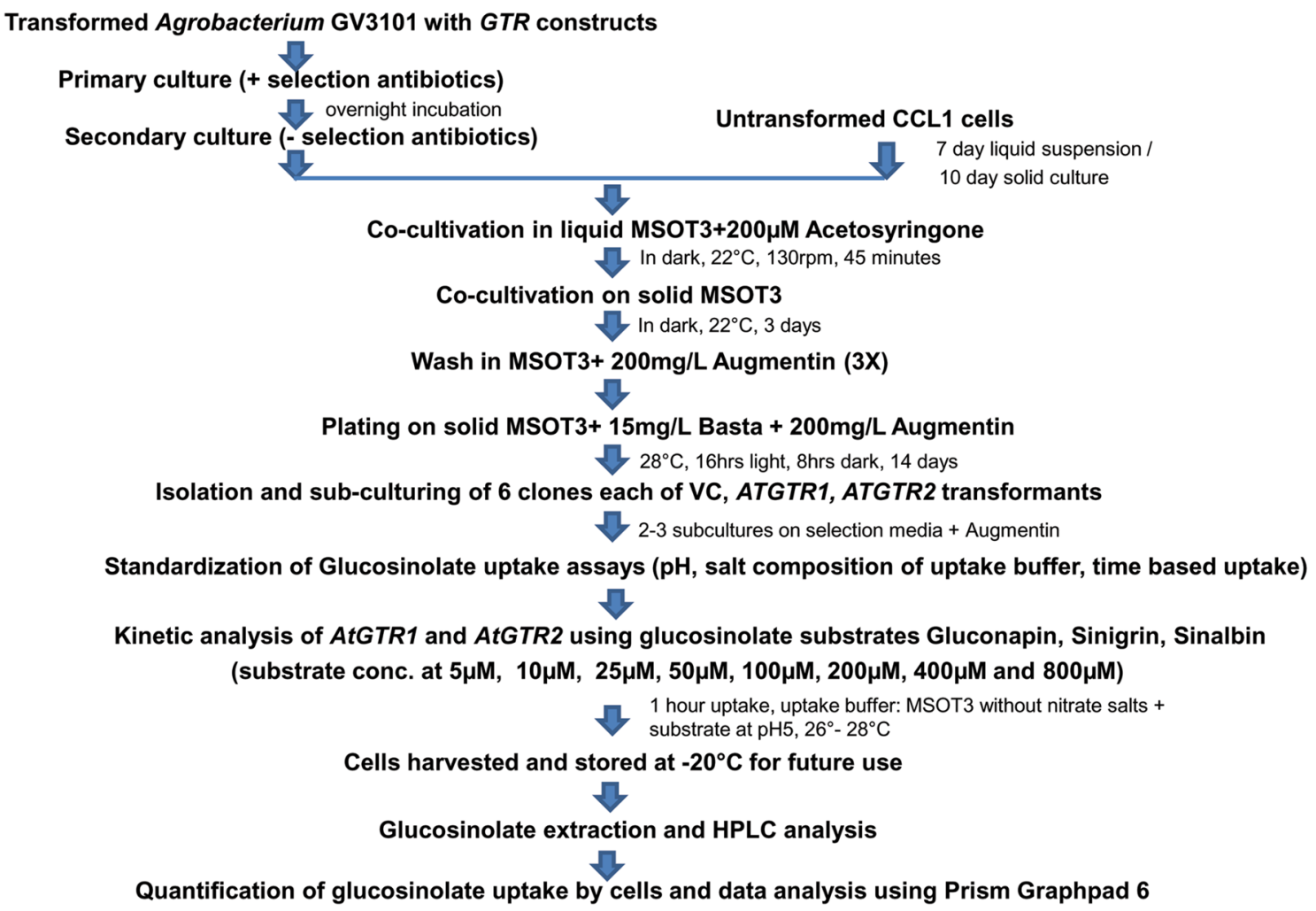

Fig. 1 Flow chart depicting generation of GTR transformed cotton cell lines (CCL-1) and subsequent performance of glucosinolate uptake assays 
a

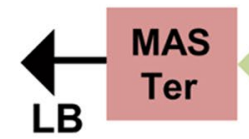

b

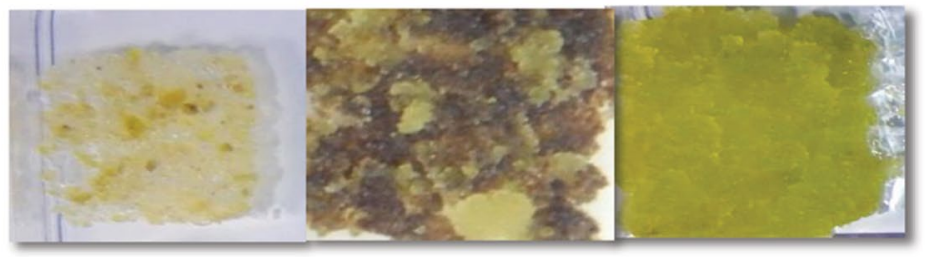

C

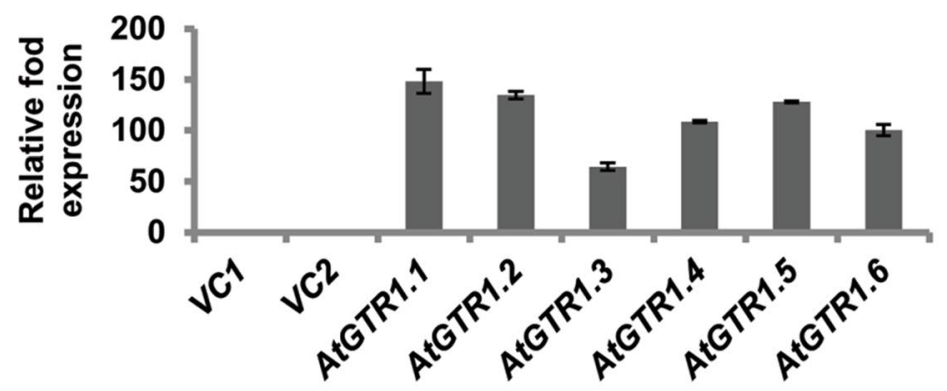

d

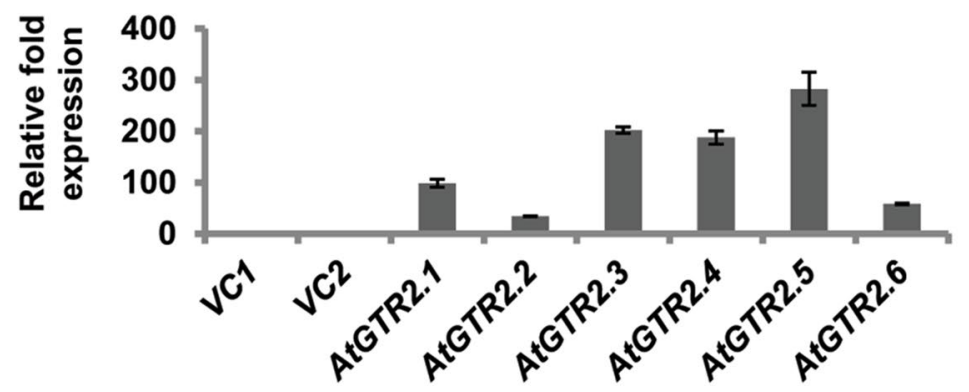

Fig. 2 Generation and validation of GTR over-expressing CCL-1. a T-DNA map representing GTR over-expression construct. b Starting from left, untransformed cells on Basta selection media, GTR transformant clones growing through dead untransformed cells on selection media, GTR transformant clone maintained on selection media; (c) and (d) qRT-PCR analysis showing relative fold expression of AtGTR1 and AtGTR2 in CCL-1 transformants, respectively (w.r.t. cotton Ubiquitin set at 100). Six clones each of AtGTR1 and AtGTR2 over-expressing CCL-1 are presented along with vector controls (VC1 and VC2)

amplification of AtGTR1 and AtGTR2 using gene specific internal primers.

Relative expression levels of AtGTR1 and AtGTR2 genes were ascertained through qRT-PCR for all the transformants using gene specific internal primers, with the ubiquitin gene as the reference gene. The AtGTR1 and AtGTR2 transformant CCL-1 showed several fold higher relative expression of their respective transgenes, whereas no GTR expression was detected in the vector control transformants (Fig. 2c, d). Relative expression levels varied across clones, which could possibly be resulting from the transgene position effect. Following the confirmation of presence of the desired transgene and expression analysis of GTRs in CCL1 transformants, a total of six independent clones of each construct were selected and maintained.

The TMHMM server 2.0 software (http://www.cbs. dtu.dk/services/TMHMM/) predicts AtGTR1 and AtGTR2 as 12 transmembrane (12-TM) proteins. To prove the usefulness of CCL- 1 as a functional analysis of transporters, we investigate the subcellular localization of AtGTR1 and AtGTR2 proteins in the heterologous system. The Pro35S:GTR1:YFP and Pro35S:GTR2:YFP fusion constructs were stably transformed in CCL-1 cells using the Agrobacterium transformation protocol. Untransformed CCL-1 cells and 
empty vector control (lacking functional YFP) served as negative controls and showed no YFP fluorescence. The GTR transformed CCL-1 cells showed a strong yellow fluorescence signal which co-localizes with the staining of the FM4-64 membrane marker dye (Fig. 3), thus demonstrating that both AtGTR1 and AtGTR2 are predominantly plasma-localized proteins, when overexpressed in CCL-1 cells.

\section{Effect of nitrate salts in uptake buffer}

Functional analysis of the GTR cell lines required prior standardization of the uptake buffer. The MSOT3 growth medium used for maintaining CCL-1 cultures comprises of a carbon source as well as an osmoticum, both being the minimal requirements for maintaining the integrity and health of the cell suspensions during the uptake assays. However, the growth medium also contains
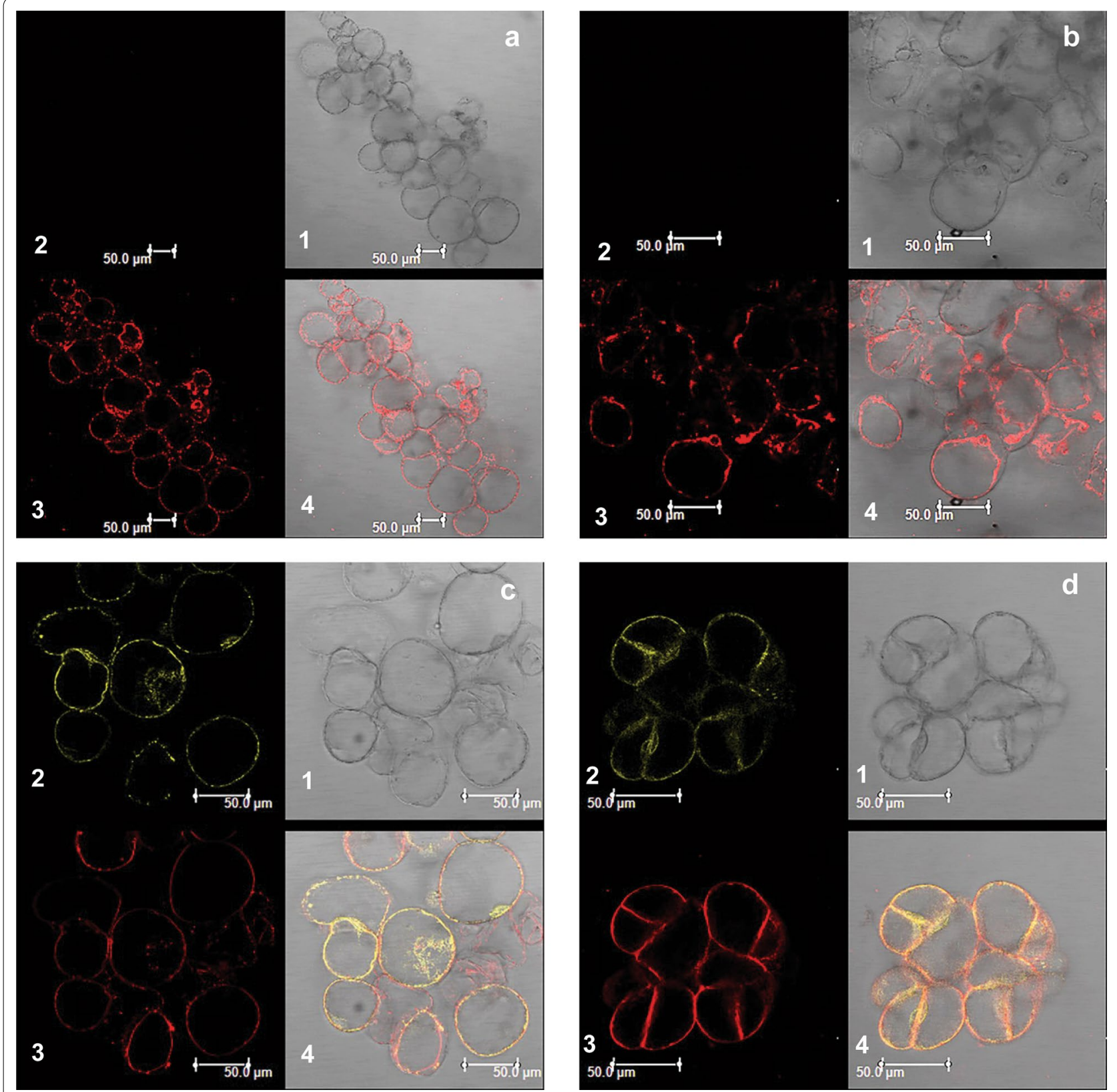

Fig. 3 Sub-cellular localization of GTR transporters in CCL-1 cells. a Untransformed CCL-1 cells, b CCL-1 cells transformed with empty vector, pEarlygate101, c AtGTR1:YFP expressing CCL-1 cells, and (d) AtGTR2:YFP expressing CCL-1 cells. For each of these panels, the bright field (1), YFP fluorescence (2), FM4-64 marker fluorescence (3), and merged (4) images are arranged in the anticlockwise order from top right 
nitrate salts in abundance ( $30 \mathrm{mM} \mathrm{KNO}_{3}$ ). Since GTR transporters have been proven to retain their affinity for nitrates, it was important to check the effect of nitrates on the transport efficiency (expressed as nmoles/g/hour) through checking glucosinolate uptake by the AtGTR transformed cells when the growth medium was used as an uptake buffer.

Uptake assays were performed on vector control and AtGTR2 expressing cells using MSOT3 growth media directly as the uptake buffer with $10 \mu \mathrm{M}$ and $100 \mu \mathrm{M}$ sinigrin, an aliphatic glucosinolate. Alternately these uptake assays were performed using MSOT3 without nitrate salts as the uptake buffer. No detrimental effect of nitrate salts elimination was observed on the integrity of the CCL-1 plasma membrane. Notably, the glucosinolate uptake by AtGTR2 expressing cells was reduced markedly to almost $50 \%$ when MSOT3 was used as the uptake buffer at a lower concentration of sinigrin $(10 \mu \mathrm{M})$ as compared to MSOT3 without nitrates (Fig. 4a). However, no significant reduction was recorded in assays performed at $100 \mu \mathrm{M}$ sinigrin.

\section{Effect of $\mathrm{pH}$ of uptake buffer on assay efficiency}

Another relevant parameter pertaining to the uptake efficiency of the cells was the $\mathrm{pH}$ of the uptake buffer. GTR transporters are dependent on protons for symporting glucosinolates. It was reported that for maximal glucosinolate uptake by Xenopus oocytes, the uptake buffer was required to be at $\mathrm{pH} 5$ [14]. Thus, to check if this held true for our system, uptake assays were performed using AtGTR2 expressing CCL-1 cells, with uptake buffers at $\mathrm{pH} 5$ and $\mathrm{pH} 6$ and $100 \mu \mathrm{M}$ sinigrin as the substrate. It was observed consistently that the cells stayed healthy and showed optimum growth at both $\mathrm{pH} 5$ and $\mathrm{pH} 6$ ruling out the possibility of erroneous results due to stress induced physiological alterations in the cell membrane. Our results showed no significant difference in GTR mediated sinigrin uptake efficiency at pH5 and pH6 (Fig. 4b).

\section{GTR expressing CCL-1 cells show time based glucosinolate uptake}

Time based uptake assays using $100 \mu \mathrm{M}$ Sinigrin shows that the glucosinolate is accumulated by cells sufficiently thus enabling detection from 30 min onwards. The uptake of glucosinolates by AtGTR1 and AtGTR2 expressing cells at a sinigrin concentration of $100 \mu \mathrm{M}$ in the transport buffer was determined at regular intervals for the duration of $24 \mathrm{~h}$. The ' 0 ' $\mathrm{hr}$ time point represents the 'control' time point at which sinigrin was not added, no sinigrin peaks were detected clearly proving the absence of any endogenous sinigrin. Uptake and the consequential time dependent accumulation of sinigrin in AtGTR1 and $A t G T R 2$ expressing cells are represented by a linear

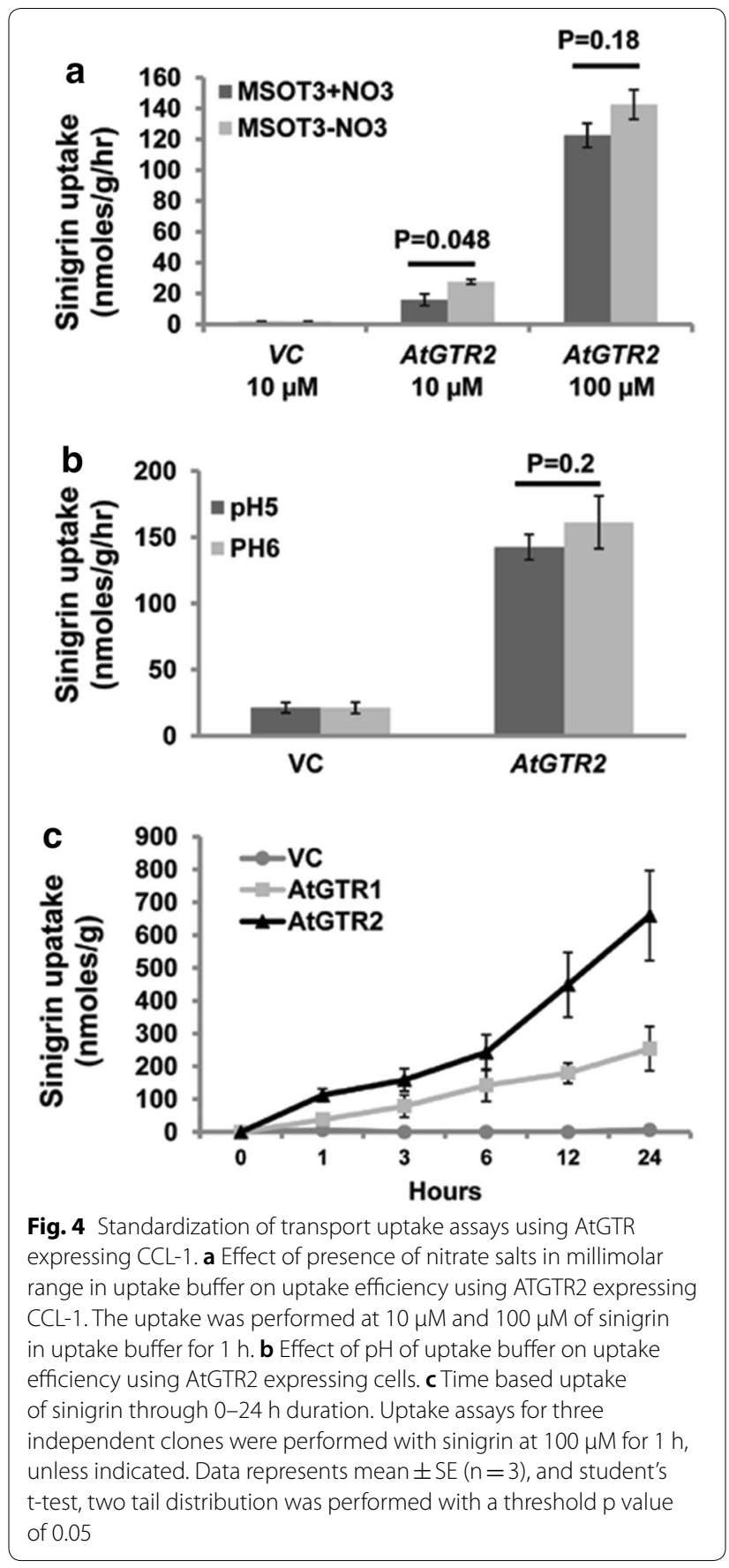

graph during the time range of $0-24 \mathrm{~h}$ (Fig. 4c). AtGTR1 expressing cells showed an average sinigrin content of $37.9 \pm 10.6 \mathrm{nmoles} / \mathrm{g}$ after 1 hour uptake, and its accumulation in the cells reaching $253.97 \pm 67.3 \mathrm{nmoles} / \mathrm{g}$ after $24 \mathrm{~h}$. Similarly, AtGTR2 expressing cells showed an average sinigrin accumulation of $112.02 \pm 19.8 \mathrm{nmoles} / \mathrm{g}$ after 1 hour uptake, the level rising to $659 \pm 137.4 \mathrm{nmoles} / \mathrm{g}$ after $24 \mathrm{~h}$. 
Functional and biochemical analysis of Arabidopsis GTRs using CCL-1

Standardization of the uptake conditions was followed by functional analysis of the GTR expressing CCL-1. Uptake assays were initially performed using three different glucosinolate substrates, namely sinigrin, gluconapin and sinalbin at $100 \mu \mathrm{M}$ glucosinolate concentration. AtGTR1 and AtGTR2 expressing cells showed several folds higher uptake of glucosinolates as compared to vector control, which showed low basal transport (Fig. 5a). Assays using $100 \mu \mathrm{M}$ gluconapin as substrate showed AtGTR1 and AtGTR2 expressing cells accumulating gluconapin at an average of $54.5 \pm 12.4 \mathrm{nmoles} / \mathrm{g} / \mathrm{hr}$ and $62.9 \pm 18$ $\mathrm{nmoles} / \mathrm{g} / \mathrm{hr}$ respectively as compared to $2.4 \mathrm{nmols} / \mathrm{g} / \mathrm{hr}$ for the vector control. $100 \mu \mathrm{M}$ sinigrin showed an average sinigrin accumulation of $17.6 \pm 2.5 \mathrm{nmoles} / \mathrm{g} / \mathrm{hr}$ and $60.9 \pm 5.8 \mathrm{nmoles} / \mathrm{g} / \mathrm{hr}$ by AtGTR1 and AtGTR2 expressing cells respectively compared to $2.3 \pm 0.6 \mathrm{nmoles} / \mathrm{g} /$ $\mathrm{hr}$ for the vector control. Further, in uptake assays with $100 \mu \mathrm{M}$ sinalbin AtGTR1 and AtGTR2 expressing cells showed an average sinalbin accumulation of around $13.2 \pm 2.3 \mathrm{nmoles} / \mathrm{g} / \mathrm{hr}$ and $27.7 \pm 2.6 \mathrm{nmoles} / \mathrm{g} /$ hr respectively as compared to $1.6 \pm 0.5 \mathrm{nmols} / \mathrm{g} / \mathrm{hr}$ of vector control. The AtGTR expressing cells showed robust uptake of both aliphatic (sinigrin, gluconapin) and aromatic (sinalbin) glucosinolates, confirming the ability of these transporters to transport both types of glucosinolates.

Since GTR transporters have a wide substrate range, kinetic analysis of these transporters can elucidate on any preferential substrate specificities. Thus, we performed kinetic analysis for AtGTR1 and AtGTR2 for glucosinolate substrates sinigrin, gluconapin and sinalbin (Fig. 5). Kinetic assays were performed over a concentration range of $10-800 \mu \mathrm{M}$ for gluconapin and a range of $10-400 \mu \mathrm{M}$ for sinigrin and sinalbin. Three to four clones representing independent transformation events and showing comparable transport efficiencies of each of the three glucosinolate substrates were selected for each of AtGTR1 and AtGTR2 expressing cell lines for kinetic analysis. The glucosinolate uptake by GTR transporters showed saturable kinetics and fitted into the MichaelisMenten curve (Fig. 5b-d), as has already been reported using oocyte assay [14]. Km values and Vmax values for AtGTR1 and AtGTR2 transporters for all of the above mentioned glucosinolate substrates were obtained using
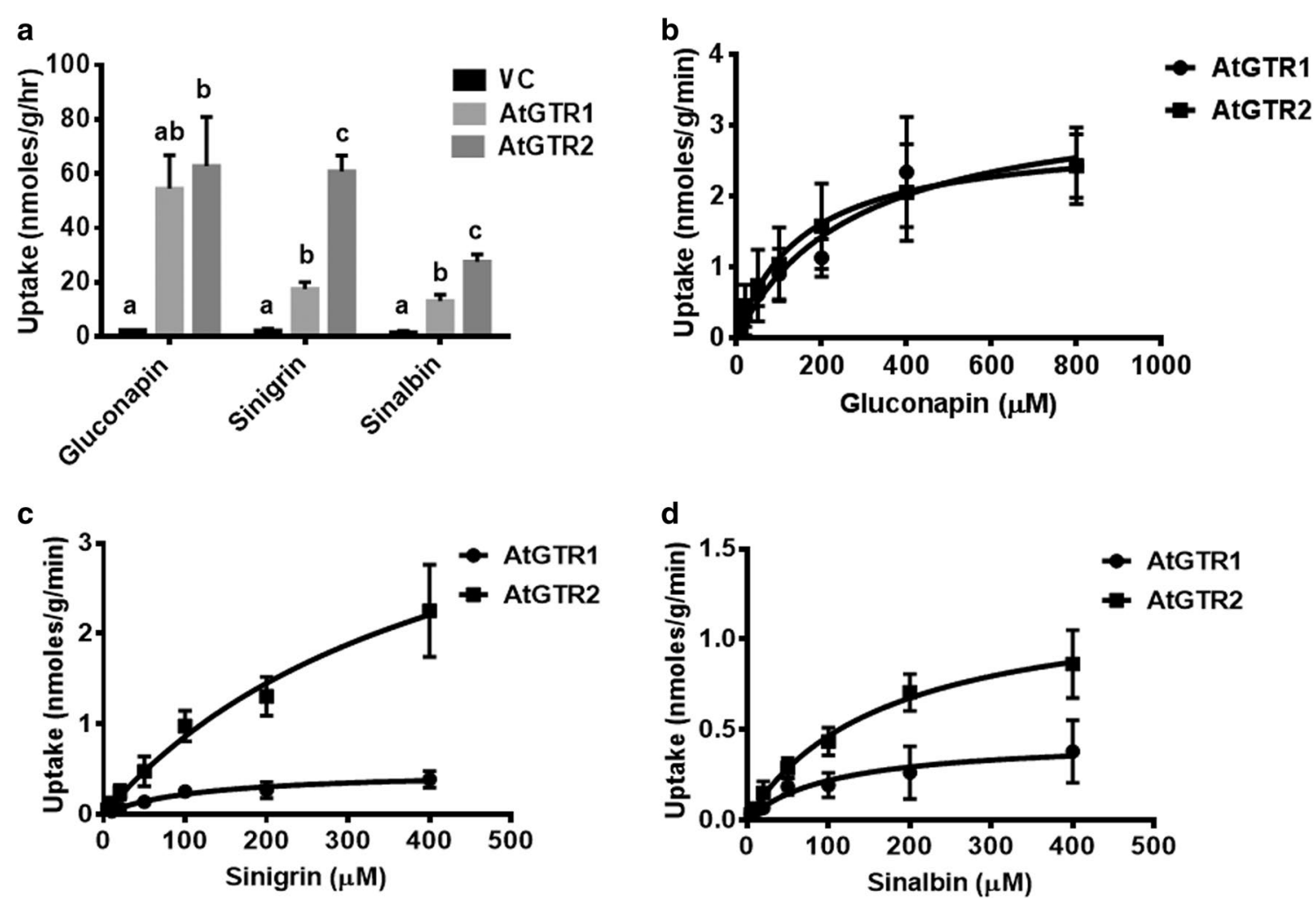

Fig. 5 Functional analysis of AtGTR expressing CCL-1 cells a Hourly uptake of sinigrin at $100 \mu \mathrm{M}$ conc. by vector control, AtGTR1 and AtGTR2 expressing CCL-1 cells. Tukey posthoc test in One-way ANOVA was performed to check for statistically significant difference in uptake between the different lines $(n \geq 3)$. b Kinetic analysis of AtGTR transporters for gluconapin $\mathbf{c}$ sinigrin, and $\mathbf{d}$ sinalbin. Uptake assays for three independent clones $(100 \mathrm{mg})$ were performed with glucosinolate concentration $(5-800 \mu \mathrm{M})$ for $1 \mathrm{~h}$. Data represents mean $\pm S E(n \geq 3)$ 
our system (Table 1). Km values for AtGTR1 for sinigrin, gluconapin and sinalbin ranged between $104.5 \mu \mathrm{M}$ and $279.1 \mu \mathrm{M}$. Further, maximum rate of either glucosinolate substrate uptake by cell lines expressing AtGTR1 ranged between $0.5 \mathrm{nmoles} / \mathrm{g} / \mathrm{min}$ and $3.4 \mathrm{nmoles} / \mathrm{g} /$ min. Km values for AtGTR2 for the three substrates ranged between $166.7 \mu \mathrm{M}$ and $436.7 \mu \mathrm{M}$. The maximum rate of either glucosinolate substrate uptake by cell lines expressing AtGTR2 ranged between $1.2 \mathrm{nmoles} / \mathrm{g} / \mathrm{min}$ and $4.6 \mathrm{nmoles} / \mathrm{g} / \mathrm{min}$. The $\mathrm{Km}$ values for glucosinolates were in the micromolar range which is expected for high affinity transporters as is the case with these transporters. Moreover, both AtGTR1 and AtGTR2 transporters appeared to have high affinity for both aliphatic and aromatic glucosinolates. Taken together, our study provides a novel strategy for performing a detailed kinetic analysis of transmembrane proteins under in vivo condition using a plant derived CCL-1 cell line.

\section{Discussion}

We generated GTR expressing CCL-1 lines (AtGTR1 and AtGTR2 expressing cells) and standardized glucosinolate uptake assays for subsequent kinetic experiments (Figs. 1 and 2). Our experiments indicated that the MSOT3 culture medium without nitrate salts was an ideal uptake buffer. As already mentioned GTR transporters are phylogenetically related to nitrate transporters and have retained the ability to transport nitrates when present in millimolar ranges [14]. The presence of very high concentration of nitrates $(30 \mathrm{mM})$ in the MSOT3 growth medium can compete with glucosinolates uptake at low glucosinolate concentrations (Fig. 4a). However, since GTR transporters are high affinity glucosinolate transporters the competitive effect of nitrates is not significant at a higher concentration of $100 \mu \mathrm{M}$. This aspect

Table 1 Biochemical characterization of Arabidopsis GTRs for different glucosinolate substrates using the cotton cell line system. Uptake assays for three independent clones $(100 \mathrm{mg})$ were performed with glucosinolate concentration (5-800 $\mu \mathrm{M})$ for 1 h. Data represents mean \pm SE

\begin{tabular}{llll}
\hline Substrate & Transporter & $\mathbf{K m}(\boldsymbol{\mu M})$ & $\begin{array}{l}\text { Vmax } \\
\text { (nanomoles/g/ } \\
\text { min) }\end{array}$ \\
\hline Gluconapin & AtGTR1 & $279.1 \pm 109$ & $3.4 \pm 0.6$ \\
Gluconapin & AtGTR2 & $153.3 \pm 59$ & $2.9 \pm 0.4$ \\
Sinigrin & AtGTR1 & $117.9 \pm 44$ & $0.5 \pm 0.07$ \\
Sinigrin & AtGTR2 & $436.7 \pm 154$ & $4.6 \pm 1.1$ \\
Sinalbin & AtGTR1 & $104.5 \pm 56$ & $0.5 \pm 0.09$ \\
Sinalbin & AtGTR2 & $166.7 \pm 40$ & $1.2 \pm 0.1$ \\
\hline
\end{tabular}

becomes relevant while performing kinetic assays in which depressed uptake at lower concentrations owing to competition from nitrates can yield exaggerated $\mathrm{Km}$ values.

Another important parameter on which the uptake efficiency might depend on was the $\mathrm{pH}$ of uptake buffer. GTR transporters are proton dependent and Xenopus assays for the GTRs indicated a distinctly higher uptake of glucosinolates at uptake buffer at $\mathrm{pH} 5$ compared to that at pH6 [14]. For our system, glucosinolate uptake efficiency was similar at uptake buffer $\mathrm{pH} 5$ and $\mathrm{pH} 6$ (Fig. 4b). This inconsistency might find a possible explanation in some key inherent differences between plant and animal cells. Plant cells have cell walls which play a key role in stress responses and growth thus requiring homeostatic regulation of the cell wall $\mathrm{pH}$ and ionic composition [19]. Moreover the plasma membrane ATPase ionic pumps in plants are $\mathrm{H}+$-ATPases whereas animal cells predominantly use $\mathrm{Na}+, \mathrm{K}+$-ATPases. Extrusion of protons by plasma membrane $\mathrm{H}+$-ATPases and homeostatic regulation cause acidification of the cell wall, creating an in built proton gradient across the membrane leading to a highly negative resting membrane potential of up to (-)200 $\mathrm{mV}$ [17]. This characteristic is especially true for plant cells involved in nutrient uptake [22]. In nature this feature helps energize proton dependent secondary active transporters such as nitrate, peptide and glucosinolate transporters (GTRs), the activity of which ensure sustenance of optimal growth and development of the plant. CCL-1 cultures which have a high nitrate requirement derive their nutrients directly from the growth media in the absence of a specialized vascular system. They also exhibit a similar rate of growth at both pH5 and pH6. They are thus expected to homeostatically maintain a natural transmembrane proton gradient within the narrow $\mathrm{pH}$ range of $5-6$ of the growth media. On the other hand, use of animal cells such as Xenopus oocytes or even plant protoplasts for such assays, would require the creation of a transmembrane proton gradient through maintenance of a specific low $\mathrm{pH}$ of the uptake buffer.

A major advantage of the CCL-1 system is the ease of transformation, maintenance and use for experimentation. Moreover, since these are individual cells, they confer the advantage of an in vitro system. In context of biochemical characterization of GTR transporters, this system enables the study of the transport mechanism of GTR transporters in isolation of any interacting/influencing biological pathways. The CCL-1 cells are fast growing and easy to manipulate. These cells stay healthy in liquid suspension cultures for up to 7 days thus permitting considerable flexibility to the system in context of duration and design of transport assays. Cultures on solid media 
grow fast and stay healthy for up to 15 days from sub-culturing, thus being available for experiments for a considerable duration.

Since the CCL-1 cells are plant based, optimum heterologous expression towards ensuring robust functioning of GTRs required no prior modifications of the GTR CDS such as codon optimization and use of specific UTRs. Further, confocal imaging of both C-terminal YFP tagged GTR expressing CCL-1 cells respectively, confirmed plasma membrane localization of the GTRs. Functionally, AtGTR expressing cells showed robust GTR mediated glucosinolate uptake. Cells harvested prior to glucosinolate addition at $0 \mathrm{~h}$ time points showed an absolute lack of endogenous glucosinolates. Time based glucosinolate uptake assays clearly indicated a linear accumulation of sinigrin with increasing time, suggesting an unambiguous role played by a carrier in the accumulation of sinigrin. Since the accumulation of sinigrin is several folds higher in case of AtGTR1 and AtGTR2 expressing cells as compared to the vector control at every time point, it can be safely concluded that the accumulation of glucosinolates in the CCL-1 transformed cell lines is the result of AtGTR1 and AtGTR2 mediated transport. Time based assays also proved that long term exposure to glucosinolate had no toxic effect on the CCL-1 cells.

Further, kinetic experiments using the GTR overexpressing CCL-1 lines also reveal the suitability of the system for functional characterization of these transporters. Functional efficiency varied between different clones possibly arising from the transgene position effect. High functioning clones exhibited high GTR mediated glucosinolate uptake consistently through several rounds of subculturing. A single transformation process of CCL-1 cells can yield numerous clones representing independent transformation events. Since transport assays are easy to perform and require a small amount of tissue, high functioning clones can be selected and maintained through regular sub culturing for reproducibility through all subsequent assays. In case of Xenopus oocytes, heterologous expression of a protein varies across oocytes of different stages of development as well as different batches [13]. Besides, clamping the plasma membrane at highly negative voltage of $(-) 200 \mathrm{mV}$ in case of electrophysiological experiments involving electrogenic plant transporters can activate endogenous voltage gated channels such as chloride channels [13] resulting in noise in the data. Thus reproducibility of results using this system depends on sound technical expertise towards selection of the right maturation stage of the oocytes, choice of appropriate controls, standardization of experiments and normalization of data. It should however also be noted that 1-hour uptake duration for kinetic analysis is expected to add a linear component to the data, as a result of time based accumulation of substrate, thus leading to slightly exaggerated $\mathrm{Km}$ values. The CCL-1 system is highly compatible with the sensitive liquid chromatography based detection systems (e.g. LC-MS) thus enabling accurate quantification of the substrate transport during early time points with limiting cell amounts, for a precise kinetic analysis.

The major findings using the system broadly conform to those obtained through investigation with established transport assay systems. Xenopus oocytes are large animal cells, a major fraction comprising of the cytosol whereas CCL-1 cells are typical plant cells characterized by a large vacuole and thin cytoplasmic lining surrounding the nucleus. Plasma membrane localized GTR transporters transport glucosinolate substrates into the cytosol [14]. Therefore, it is not possible to obtain a sharp comparison for robustness of the GTR mediated glucosinolate uptake between the two systems. Overall, the biochemical characteristics of AtGTR1 and AtGTR2 transporters elucidated through transport assays performed using our CCL-1 system are consistent with those obtained through functional characterization of these transporters using the Xenopus system [7, 14]. The transporters exhibit saturable kinetics, fitting perfectly into the Michaelis-Menten curve. These transporters showed high affinity for both aliphatic and aromatic glucosinolates with $\mathrm{Km}$ values for both substrates in $\mu \mathrm{M}$ ranges. The ability of nitrates to competitively reduce glucosinolate uptake by GTR transporters is also consistent with observations in the previous study. However, key inherent differences between heterologous systems stemming from their different biological origins make it difficult to draw detailed comparisons [13]. This is because major biochemical differences, such as that in the resting membrane potential, are expected in the plasma membranes of the plant based CCL-1 cells and animal based Xenopus oocytes. The differences between the plant based and animal based systems are also reflected in the $\mathrm{pH}$ dependency of the Xenopus and CCL-1 transport assay systems. The CCL-1 cells appear to offer the microenvironment closest to that in which GTRs function in nature. However, a limitation to our system is that it is not suitable for determining the proton dependence of plant transporters.

Due to efficient functioning of the AtGTRs, the CCL-1 system would be a suitable heterologous system for functional characterization of transporters encoded by different GTR homologs. This plant cell system is thus well suited for elucidating possible sub-functionalization between GTR paralogs and orthologs present in Brassica species. Moreover this system shows scope of use for establishing structure function relationships through mutational studies. Plant transporters are very diverse 
and their correct expression and functioning can be governed by numerous underlying biological aspects, thus creating a requirement for different heterologous expression systems to choose from. Due to all the mentioned advantages of the CCL-1 system, this cotton cell line system might hold promise for use in functional characterization of other plant secondary metabolite transporters such as phytohormone transporters. No phytohormones are required in the CCL-1 culture media. Being a plant based system, the CCL-1 cells might have some basal level of endogenous plant hormones which can be ascertained through vector controls towards subsequent data normalization. This was the strategy used for successful functional characterization of abscisic acid and auxin transporters in [10] and [2] respectively using the plant based BY-2 system.

\section{Conclusion}

We have developed a novel plant based heterologous system for functional characterization of GTR transporters. We developed GTR overexpressing cotton cell lines, which showed robust GTR mediated glucosinolate uptake and can be maintained on solid media or as liquid cell suspensions. Due to their high GTR mediated glucosinolate uptake efficiency, they are ideal for kinetic studies and elucidation of differential substrate specificities of GTR homologs. Thus, the CCL- 1 system is well suited for studying possible sub-functionalization between GTR paralogs and orthologs in polyploid Brassica species. Moreover, the CCL-1 system holds promise for use in investigation of membrane transporters for secondary metabolites.

\section{Methods \\ Isolation and cloning of Arabidopsis GTR transporters}

Total RNA was isolated from 3 weeks old Arabidopsis Col-0 leaves using Spectrum Plant Total RNA Kit (Sigma). cDNA was synthesized from the extracted RNA using Primescript First Strand cDNA Kit (Takara). Coding sequences (CDS) of $A t G T R 1$ and AtGTR2 genes were amplified using gene specific primers (Table 2) from the cDNA with Phusion High Fidelity DNA polymerase (ThermoFisher Scientific), cloned into pENTR/D-TOPO directional cloning entry vector and confirmed using sequencing. The AtGTR1 and AtGTR2 CDS were subsequently mobilized into pEarleyGate100 vector through gateway cloning. The destination vectors containing the AtGTR1 and AtGTR2 inserts were finally transformed into Agrobacterium tumefaciens GV3101. The pEarleyGate100 vector was used as the control construct.

\section{Maintenance and transformation of CCL1}

The fast growing cotton cell lines (CCL-1) were obtained from Dept. of Genetics, Univ. of Delhi, South Campus. These cell lines are derived from nonembryogenic calli originating from cotyledons of Gossypium hirsutum var Coker310FR [21]. They are maintained as friable calli on solid MSOT3 media, pH5.8 at $28^{\circ} \mathrm{C}, 16 \mathrm{~h}$ light and $8 \mathrm{~h}$ dark with no phytohormone requirement. Solid MSOT3 media is MS media with additional KNO3 $(1.9 \mathrm{gm} / \mathrm{L})$ and $0.2 \%$ Phytagel. Alternately, $500 \mathrm{mg}$ of CCL- 1 calli can be

Table 2 List of primers used in this study

\begin{tabular}{lll}
\hline S. no. & Primer & Sequence $\mathbf{( 5}^{\prime} \mathbf{- 3}^{\prime} \mathbf{)}$ \\
\hline Gene amplification & & \\
1 & At3G47960 GTR1 FP & CACCATGAAGAGCAGAGTCATTCTTAACC \\
2 & At3G47960 GTR1 RP & TCAGACAGAGTTCTTGTCTTGTAGC \\
3 & At5G62680 GTR2 FP & CACCATGGAGAGAAGCCTCTTGAAC \\
4 & At5G62680 GTR2 RP & TCAGGCAACGTTCTTGTCTTGCTG \\
Transgene insertion validation & & \\
5 & Bar FP & GCTCTACACCCACCTGCTGAA-3' \\
6 & Bar RP & TCAGATCTCGGTGACGG-3' \\
7 & GTR1 internal FP & ATCAACAGTTTCTTCAACTGGT \\
8 & GTR2 internal FP & TGGGGCTGATCAGTTTAACC \\
9 & GTR1/GTR2 internal RP & ACTGCTTGTAGTAAAACTCCAT \\
Transgene expression validation & & \\
10 & AtGTR1(RT) FP & GAATCGGAGCTGGGTTTACA \\
11 & AtGTR2(RT) FP & TGGCATTTTCTTCGCTACCGC \\
12 & GTR1/GTR2 (RT) RP & ACTGCTTGTAGTAAACTCCAT \\
13 & Ubuiquitin FP & GGTGGGATGCAAATCTTCGTGAAAC \\
\hline
\end{tabular}


inoculated in $50 \mathrm{ml}$ liquid MSOT3 in $250 \mathrm{ml}$ flask and maintained at the afore-mentioned conditions on an orbital shaker at $130 \mathrm{rpm}$.

Cell lines were transformed as mentioned in [21]. Briefly, 7 day old liquid cell suspensions or 10 day old solid cotton cell cultures are ideal for transformation. Approx. $500 \mathrm{mg}$ of cotton cells was co-cultivated with Agrobacterium in liquid MSOT3 containing $200 \mu \mathrm{M}$ Acetosyringone in dark at $22{ }^{\circ} \mathrm{C}$ for an hour followed by cocultivation on solid MSOT3, pH5.8 for 3 days in dark at $22{ }^{\circ} \mathrm{C}$. Finally cells were washed three times with liquid MSOT3 media containing $200 \mathrm{mg} / \mathrm{L}$ Augmentin; plated on solid media containing Basta $(15 \mathrm{mg} / \mathrm{L})$ and Augmentin $(250 \mathrm{mg} / \mathrm{L})$; and kept at $28^{\circ} \mathrm{C}, 16 \mathrm{~h}$ light and $8 \mathrm{~h}$ dark. After 2 weeks transformants were visible as yellow and green calli.

These calli were sub-cultured every fortnight. Transformants were confirmed by isolating genomic DNA using CTAB method and PCR amplification using BplR gene, AtGTR1 and AtGTR2 specific internal primers (Table 2). Gene expression was ascertained through qRT-PCR. RNA was isolated from $200 \mathrm{mg}$ of transformed cells using Trizol method, cDNA was synthesized using High Capacity cDNA Reverse Transcription Kit (ThermoFisher Scientific). AtGTR1 and AtGTR2 specific internal primers were used for qRT-PCR and relative expression was quantified using cotton Ubiquitin as the reference gene.

\section{Subcellular localization of AtGTR1 and GTR2 proteins}

To generate a proCaMV35S:AtGTR1/2:YFP fusion construct, AtGTR1 and AtGTR2 CDS lacking the stop codons were mobilized to the $\mathrm{C}$-terminal YFP fusion vector, pEarlygate101. Constructs were transformed into CCL-1 cells through Agrobacterium mediated transformation. CCL-1 cells expressing tagged proteins were teased in MSOT3 medium on a slide and stained with FM4-64 membrane marker dye at a working concentration of $2 \mu \mathrm{g} / \mathrm{ml}$ (Life Technologies, ThermoFisher). The slides were imaged immediately after staining, with the Leica TCS SP5 confocal microscope using appropriate filters for YFP $(514 / 527 \mathrm{~nm})$ and FM4-64 $(515 / 640 \mathrm{~nm})$. CCL-1 cells containing empty vector pEarlygate101 (with non-functional YFP) was used as the negative control.

\section{Glucosinolate uptake assays by GTR transformed CCL1}

For glucosinolate uptake assays both 7-15 days old healthy callus cultures and 7 day old liquid suspension cultures can be used. Liquid MSOT3 without nitrate salts at pH5 was used as transport uptake buffer. For time based uptake assays, cell suspensions of transformed cell lines was obtained by adding $6 \mathrm{~g}$ cells in $30 \mathrm{ml}$ MSOT3, pH5 in $250 \mathrm{ml}$ conical flasks and kept on an orbital shaker at $130 \mathrm{rpm}, 28{ }^{\circ} \mathrm{C}$. Approx. $500 \mathrm{mg}$ of cells were harvested in $2 \mathrm{ml}$ collection tubes prior to substrate addition for $0 \mathrm{~h}$ readings. Glucosinolate $(100 \mu \mathrm{M}$ sinigrin $)$ was then added and 100-500 mg cells were harvested at specific time points in $1.5 \mathrm{ml}$ microcentrifuge tubes, washed thrice by adding $1 \mathrm{ml} \mathrm{MSOT3}$, centrifugation at $4000 \mathrm{rpm}, 30 \mathrm{~s}$ followed by discarding of supernatant and storage at $-80{ }^{\circ} \mathrm{C}$. Kinetic experiments were performed directly in $2 \mathrm{ml}$ safe lock microcentrifuge tubes. About $100 \mathrm{mg}$ cells were added to $1 \mathrm{ml}$ uptake buffer, mixed gently to create a suspension. The tubes were fixed on an orbital shaker at $130 \mathrm{rpm}$ after substrates were added at specific concentrations, cells were harvested after $1 \mathrm{~h}$ and washed and stored as before.

\section{Glucosinolate extraction and HPLC analysis}

Extraction of glucosinolates was done as mentioned in [11]. Briefly, the harvested cells were crushed in $70 \%$ methanol with sinalbin as internal standard (IS) in case of use of sinigrin and gluconapin as substrates, and sinigrin as IS where sinalbin was used as substrate was used for extraction, followed by incubation at $75{ }^{\circ} \mathrm{C}$. The supernatant was loaded on 96 well plate containing Sephadex columns. The columns were washed with $70 \%$ methanol, twice with HPLC grade water and a final wash with 0.02 M MES buffer ( $\mathrm{pH}$ 5.2). Finally, Sulphatase was added and plate was incubated at room temperature in dark for a minimum of $18 \mathrm{~h}$. The glucosinolates in each well were eluted in HPLC grade water.

Samples were analyzed using Shimadzu CLASS-VP V6.14 HPLC machine. The program was set at a Solvent B (Acetonitrile) gradient of $1-19 \%$ through a $25 \mathrm{~min}$ cycle. The flow rate was maintained at $1 \mathrm{ml} / \mathrm{min}$. and detection was made at $229 \mathrm{~nm}$. The glucosinolates uptake by cells was determined by identifying the substrate peak by referencing it with known internal standard peaks.

\section{Intact glucosinolates extraction}

Sinigrin hydrate was obtained from Merck, whereas gluconapin and sinalbin were extracted from Brassica juncea and Sinapis alba seeds, respectively using a previously described protocol [23]. Briefly, 20 gms of seeds was nicely crushed in $70 \%$ Methanol and centrifuged. Supernatant was transferred to fresh bottle and was reextracted in $70 \%$ methanol. Supernatants from both extractions were combined and passed through Sephadex $\mathrm{col}$. The column was washed three times with $2 \mathrm{ml}$ formic acid/iso-propanol/water (3:2:5), four times with HPLC grade water. Glucosinolates were eluted into absolute ethanol through use of $0.5 \mathrm{M} \mathrm{K}_{2} \mathrm{SO} 4 / 3 \%$ iso-propanol. Supernatant was evaporated; residue re-suspended in $70 \%$ methanol and kept at $-20{ }^{\circ} \mathrm{C}$ for $30 \mathrm{~min}$. The tube was centrifuged and supernatant was treated with three volumes of absolute ethanol. Pure glucosinolates was 
precipitated out through evaporation. The authenticity of the glucosinolate peaks has been described in our recent study [1] and a representative HPLC chromatogram has been provided as Additional file 1: Figure S1.

\section{Determination of kinetic parameters}

One-way ANOVA, Tukey posthoc test was performed with SPSS software for comparison between the means of glucosinolate uptake at $100 \mu \mathrm{M}$ of gluconapin, sinigrin and sinalbin, by vector controls, AtGTR1 and AtGTR2 expressing CCL1 lines. 3-4 clones showing comparable uptake were selected for each line for further kinetic analysis.

Kinetics graphs, average $\mathrm{Km}$ and Vmax values with standard errors were derived using Graphpad 6 using nonlinear regression analysis and fitting into the Michaelis-Menten equation. In order to study the effect of $\mathrm{pH}$ and nitrates in transport assay buffer, uptake data was subjected to student's $t$ test, two tailed distribution with a threshold $p$ value of 0.05 .

\section{Supplementary information}

Supplementary information accompanies this paper at https://doi. org/10.1186/s13007-020-00618-0.

Additional file 1: Figure S1. HPLC chromatogram showing the peaks of purified glucosinolates used in this study. The identity of glucosinolates was based on similar retention time of peaks for sinigrin (SIN), sinalbin $(4 \mathrm{OHB})$ and gluconapin (GNA) using the method described in our recent study (Bajpai et al [1]

\section{Abbreviations}

CCL-1: Cotton cell suspension line-1; GTR: Glucosinolates transporter; HPLC: High performance liquid chromatography; MSOT3: MS media with additional KNO3 (1.9 g/L); nmols/g/min: Nanomoles per gram per minute; qRT-PCR: Quantitative reverse transcription polymerase chain reaction.

\section{Acknowledgements}

We sincerely acknowledge Prof. Deepak Pental, CGMCP, Department of Genetics, UDSC, New Delhi, India for providing the CCL-1 culture. We also thank Ms. Avni Mann and Mr. Vinod Kumar for their help in this study.

\section{Authors' contributions}

NCB conceived the research. NCB and DMN planned and designed all experiments. DMN and JK generated GTR overexpression constructs. DMN and AKS generated the GTR expressing cell lines, and JK maintained the transformed CCL-1 lines. DMN standardized and performed kinetic experiments. GCA validated transgene insertion and expression. DMN performed localization studies. NCB contributed reagents or analytical tools. DMN and NCB analysed data and wrote the manuscript. All authors read and approved the manuscript.

\section{Funding}

Research was supported by Department of Biotechnology-IYBA (BT/06/ IYBA/2012) project grants to NCB. DMN was supported from research fellowship of UGC (India) and NIPGR (New Delhi).

\section{Availability of data and materials}

All data generated or analyzed during this study are included in this published article.
Ethics approval and consent to participate

Not applicable.

\section{Consent for publication}

Not applicable.

\section{Competing interests}

The authors declare that they have no competing interests.

\section{Author details}

${ }^{1}$ National Institute of Plant Genome Research, Aruna Asaf Ali Marg, New Delhi 110067, India. ${ }^{2}$ Department of Genetics, CGMCP, University of Delhi South Campus, New Delhi 110021, India.

Received: 24 August 2019 Accepted: 15 May 2020

Published online: 24 May 2020

\section{References}

1. Bajpai PK, Reichelt M, Augustine R, Gershenzon J, Bisht NC. Heterotic patterns of primary and secondary metabolites in the oilseed crop Brassica juncea. Heredity. 2019;123:318-36.

2. Cho M, Lee SH, Cho H-T. P-glycoprotein4 displays auxin efflux transporterlike action in arabidopsis root hair cells and tobacco cells. Plant Cell. 2007;19:3930-43.

3. Dumont JN. Oogenesis in Xenopus laevis (Daudin). I. Stages of oocyte development in laboratory maintained animals. J Morphol. 1972;136:153-79.

4. Froissard M, Belgareh-Touzé N, Buisson N, Desimone M, Frommer WB, Haguenauer-Tsapis R. Heterologous expression of a plant uracil transporter in yeast: improvement of plasma membrane targeting in mutants of the Rsp5p ubiquitin protein ligase. Biotechnol J. 2006;1:308-20.

5. Gaymard F, Cerutti M, Le Horeau C, Lemaillet G, Urbach S, Ravallec M, Devauchelle G, Sentenac H, Thibaud J. The baculovirus/insect cell system as an alternative to xenopus oocytes. J Biol Chem. 1996;271:22863-70.

6. Haro R, Bañ uelos MA, Senn ME, Barrero-Gil J, Rodrı 'guez A. HKT1 mediates sodium uniport in roots. pitfalls in the expression of HKT1 in yeast. Plant Physiol. 2005;139:1495-506.

7. Jørgensen ME, Xu D, Crocoll C, Ramírez D, Motawia MS, Olsen CE, Nour Eldin $\mathrm{HH}$, Halkier BA (2017) Origin and evolution of transporter substrate specificty within the NPF family. eLIFE. 6:e19466.

8. Kanno Y, Hanada A, Chiba Y, Ichikawa T, Nakazawa M, Matsui M, Koshiba T, Kamiya Y, Seo M. Identification of an abscisic acid transporter by functional screening using the receptor complex as a sensor. PNAS. 2012;109:9653-8.

9. Kubeš M, Yang H, Richter GL, Cheng Y, Młodzinska E, Wang X, Blakeslee JJ, Carraro N, Petrasek J, Zazımalova E, Hoyerova K, Peer WA, Murphy AS. The Arabidopsis concentration-dependent influx/efflux transporter $\mathrm{ABCB} 4$ regulates cellular auxin levels in the root epidermis. Plant J. 2012;69:640-54.

10. Kang J, Hwang JU, Lee M, Kim YY, Assmann SM, Martinoia E, Lee Y. PDRtype $A B C$ transporter mediates cellular uptake of the phytohormone abscisic acid. Proc Natl Acad Sci USA. 2010;107(5):2355-60.

11. Kumar P, Augustine R, Singh AK, Bisht NC. Feeding behaviour of generalist pests on Brassica juncea: implication for manipulation of glucosinolate biosynthesis pathway for enhanced resistance. Plant Cell Environ. 2017:40:2109-20.

12. Madsen SR, Olsen CE, Nour-Eldin HH, Halkier BA. Elucidating the role of transport processes in leaf glucosinolate distribution. Plant Physiol. 2014;166(3):1450-62.

13. Miller AJ, Zhou JJ. Xenopus oocytes as an expression system for plant transporters. Biochem Biophys Acta. 2000;1465:343-58.

14. Nour Eldin HH, Andersen TE, Burow M, Madsen SR, Jørgensen ME, Olsen CE, Dreyer I, Hedrich R, Dietmar G, Halkier BA. NRT-PTR transporters are essential for translocation of glucosinolates defence compounds to seeds. Nature. 2012;488:531-4.

15. Nour-Eldin HH, Madsen SR, Engelen S, Jørgensen ME, Olsen CE, Andersen JS, Seynnaeve D, Verhoye T, Fulawka R, Denolf P, Halkier BA. Reduction of antinutritional glucosinolates in Brassica oilseeds by mutation of genes encoding transporters. Nat Biotechnol. 2017;35:377-82. 
16. Nour-Eldin HH, Nørholm MHH, Halkier BA. Screening for plant transporter function by expressing a normalized Arabidopsis full-length cDNA library in Xenopus oocytes. Plant Methods. 2006;2:1-17.

17. Palmgren MG. $\mathrm{H}^{+}$-ATPases: powerhouses for nutrient uptake. Annu Rev Plant Physiol Plant Mol Biol. 2001;52:817-45.

18. Saito H, Oikawa T, Hamamoto S, Ishimaru Y, Kanamori-Sato M, Sasaki-Sekimoto Y, Utsumi T, Chen J, Kanno Y, Masuda S, Kamiya Y, Seo M, Uozumi N, Ueda M, Ohta $\mathrm{H}$. The jasmonate-responsive GTR1 transporter is required for gibberellin-mediated stamen development in Arabidopsis. Nat Commun. 2015;6(1):1.

19. Sattelmacher B. The apoplast and its significance for plant mineral nutrition. New Phytol. 2001;149:167-92.

20. Sauer N, Caspari T, Klebl F, Tanner W. Functional expression of the Chlorella hexose transporter in Schizosaccharomyces pombe. Proc Nat Acad Sci. 1990;87:7949-52.

21. Singh AK, Pental D. Selection and genetic transformation of a fastgrowing cell line in cotton (Gossypium hirsutum) for transgene expression studies. J Plant Biochem Biotechnol. 2015;24(2):225-32.

22. Sondergaard ET, Schulz A, Palmgren MG. Energization of transport processes in plants. roles of the plasma membrane $\mathrm{H}+$-ATPase. Plant Physiol. 2004;136:2475-82.
23. Thies $W$. Isolation of sinigrin and glucotropaeolin from cruciferous seeds. Fett Wiss Technol. 1988;90:311-4.

24. Wittstock U, Chen S, Halkier BA. A method for expression cloning of transporter genes by screening yeast for uptake of radiolabelled substrate. J Exp Bot. 2000;51:955-60.

25. Xu D, Hanschen FS, Witzel K, Nintemann SJ, Nour- Eldin HH, Schreiner $\mathrm{M}$, Halkier BA. Rhizosecretion of stele-synthesized glucosinolates and their catabolites requires GTR-mediated import in Arabidopsis. J Exp Bot. 2017;68:3205-14.

26. Xu D, Hunziker P, Koroleva O, Blennow A, Crocoll C, Schulz A, Nour-Eldin $\mathrm{HH}$, Halkier BA. GTR-mediated radial import directs accumulation of defensive glucosinolates to sulfur-rich cells (S-cells) in phloem cap of inflorescence stem of Arabidopsis thaliana. Mol Plant. 2019;12:1474-84.

\section{Publisher's Note}

Springer Nature remains neutral with regard to jurisdictional claims in published maps and institutional affiliations.
Ready to submit your research? Choose BMC and benefit from:

- fast, convenient online submission

- thorough peer review by experienced researchers in your field

- rapid publication on acceptance

- support for research data, including large and complex data types

- gold Open Access which fosters wider collaboration and increased citations

- maximum visibility for your research: over $100 \mathrm{M}$ website views per year

At BMC, research is always in progress.

Learn more biomedcentral.com/submissions 